bile acids chenodeoxychotic acid cholic acid enterohepatic circulation lithocholic acid radioimmunoassay sulfolithocholylglycine

\title{
Serum Bile Acids in Newborns and Children
}

\author{
L. BARBARA, "2"1" R. LAZZARI, A. RODA, R. ALDINI, D. FESTI, C. SAMA. A. M. MORSELli, \\ A. COLLINA, F. BAZZOLI, G. MAZZELLA, AND E. RODA \\ Department of Gastroenterology" and Pediatrics, Institute of Chemistry "G. Ciamician," University of Bologna, Italy"
}

\begin{abstract}
Summary
A specific and sensitive radioimmunoassay for cholic, chenodeoxycholic, and lithocholic acid conjugates and for sulfolithocholylglycine was used to measure serum bile acids (BA) in infants and children.

Elevated cholic and chenodeoxycholic acid values were observed in the first year of life in fasting infants. Newborn babies presented high levels of primary BA not correlated with those of the mothers. In premature newborn babies who had not yet been fed, meal induced a considerable reduction in the primary BA levels in serum. In normally fed babies, meal induced a significant increase in the primary BA levels in serum.

These data suggest a progressive maturity throughout the first year of life of the serum BA determinants, i.e., gallbladder emptying, intestinal motility and absorption, and hepatic uptake.
\end{abstract}

\section{Speculation}

Various anatomical sections forming the enterohepatic circulation of bile acids may exhibit a different degree of maturity in newborn babies and children and may thus influence the dynamics of the enterohepatic circulation and in turn the serum levels of bile acids.

In the adult, serum bile acids (BA) concentrations depend on the hepatic uptake and on the mass of $B A$ reaching the liver from the portal stream $(3,7)$.

Experimental studies in animals and preliminary observations in man suggest that in physiologic conditions the hepatic uptake operates very far from saturation and that the fractional hepatic clearance may therefore be considered as a constant. The major determinant of serum BA levels is consequently considered to be intestinal input, which in turn depends on hepatic synthesis and secretion, gallbladder storage, and intestinal absorption of BA These factors should be borne in mind in evaluating the determinants of serum BA levels in newborns and children. although they may not be sufficient.

In fact, BA metabolism during this period of life is complex and has not yet been fully elucidated. In the neonate, several critical steps of enterohepatic circulation (EHC), which in the adult contribute to BA pool conservation, are not completely developed. For instance, the gallbladder storage capacity is lower than in the adult $(6,10)$, the active absorption capacity of the ileum is impaired (8), intraluminal BA concentrations are low (11), and cholic and chenodeoxycholic acid pools are reduced in size (19).

Few and conflicting data are available on serum BA concentrations and the relative patterns in infants and children $(1,5,16)$, probably because of the large amounts of sera needed for the technique (gas-liquid chromatography) used.

After the development of a radioimmunoassay for BA (17) it has been possible to determine serum BA for pathophysiologic research and clinical use.

The aims of the present study were to: (1) establish the normal range of the primary BA together with the ratio between conjugated lithocholic acid (CLCA) and sulfolithocholylglycine (SLCG) in the fasting serum of infants and children of various ages; (2) assay fasting serum BA levels in newborns before the first feed and in fasting (fed) neonates; (3) evaluate the diurnal variations in these BA levels after meals; (4) establish the relationship between mother and newborn sera by assaying serum BA levels in mothers, babies, and the umbilical cord blood.

\section{MATERIALS AND METHODS}

Ninety children ( 45 males and 45 females), divided into nine subgroups according to age ( 0 to 12 years), were studied. Informed consent was obtained from the participating families. The first group comprised premature infants, all of whom were fasting ( 3 hr after last meal).

The effect of food (human milk) on serum BA levels was examined in 10 premature and 10 normal babies at the third hr of life.

The effect of meal was also studied in three previously fed infants, 7 days old, the first of whom was premature and the others of whom were full-term babies. Blood samples were collected at 30-min intervals over a 3-hr period.

BA were also measured in the umbilical cord blood of 20 fullterm babies in normal weight (never fed) and in the blood of fasting babies and mothers.

Serum levels of conjugated cholic acid (CCA), conjugated chenodeoxycholic acid (CCDCA), and CLCA were assayed in each sample by a specific radioimmunoassay, according to Simmonds et al. (17) and modified by us $(13,14)$. SLCG was measured using a commercial kit (SLCG-RIA; Abbott Laboratories, North Chicago, Il).

\section{RESULTS}

The results of the four BA, CCA, CCDCA, CLCA, and SLCG are shown in Figure 1. Serum fasting levels of CCA and CCDCA, which in the first year of life are significantly higher than those in normal adult, gradually decrease to adult levels by the end of the first year. The CCA/CCDCA ratio remains unchanged; in fact, as in the adult, CCDCA predominate.

The highest levels of primary BA in serum are observed in premature infants at birth.

Serum levels of CLCA and SLCG in infants, on the contrary, are similar to those in the adult. No sex-related differences were observed for any of the BA.

Serum BA levels in never-fed newborn babies, both premature and normal, and in those already fed, but in fasting conditions ( 3 $\mathrm{hr}$ after the last meal) are shown in Figure 2. In premature infants, serum CCA and CCDCA levels decrease significantly after the first meal in life.

No statistical differences are observed between the two groups of normal infants considered.

Meal induces a significant increase in the two primary conjugates serum BA in all the three fed infants (Fig. 3). In comparison to the adult pattern $(3,7), C C A$ peaks higher and later than 

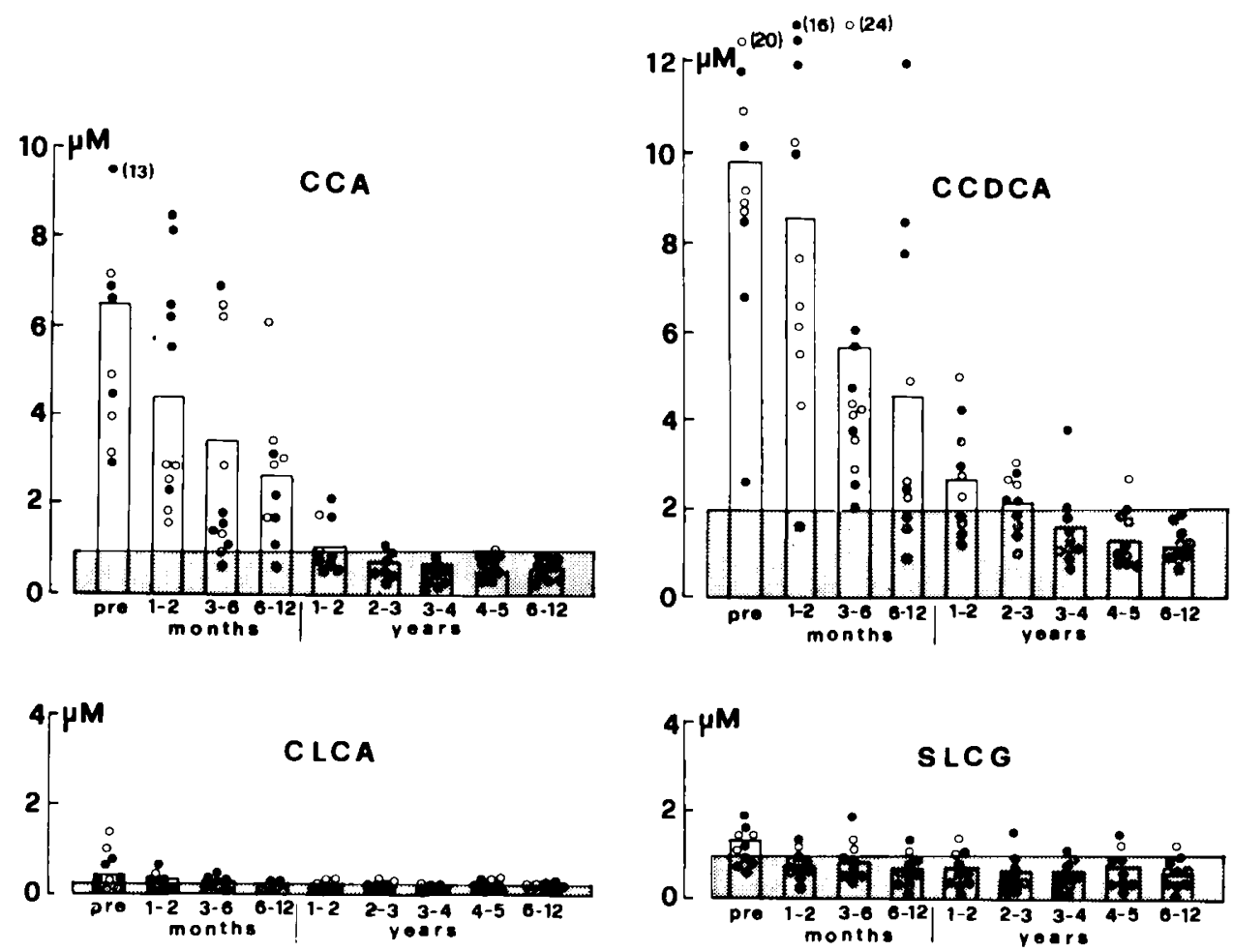

Fig. 1. Serum BA concentrations in 90 children [ 45 males $(\Theta)$ and 45 females $(O)]$ in relation to age (mean value). Shaded area, adult normal values.

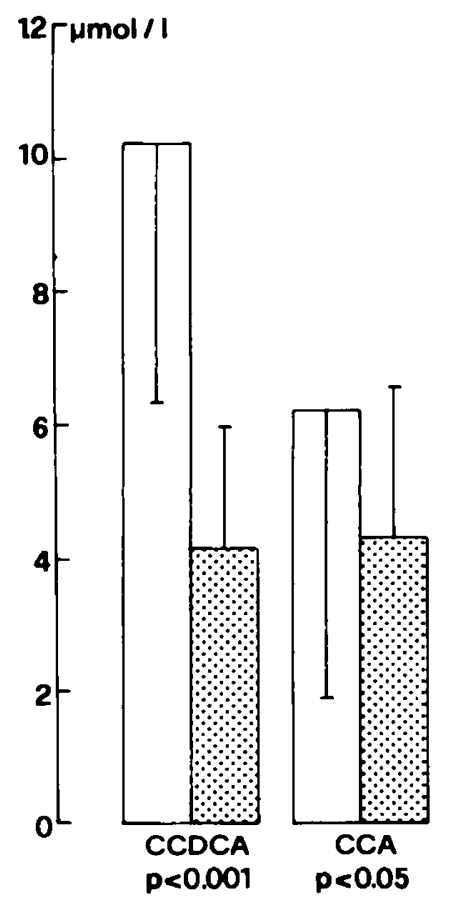

PREMATURE BABIES

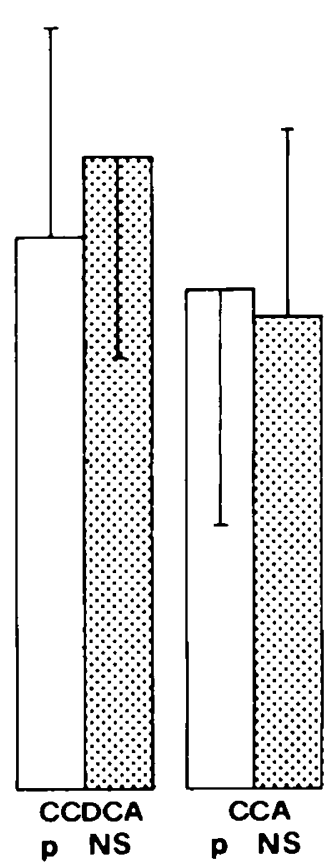

NORMAL BABIES

Fig. 2. Serum BA concentrations in 20 premature and 20 normal babies never fed $(\square)$ and normally fed (圈) but in fasting conditions ( 3 hr after the latter meal) (mean \pm S.D.).

CCDCA and returns to basal levels more slowly showing a biphasic elevation.

Serum levels of CCA, CCDCA, CLCA, and SLCG in the mother, the umbilical cord, and the baby are shown in Figure 4. The serum CCA and CCDCA levels of the mother are within the normal adult range $(3,13)$, but those of the baby are higher and show the same characteristics as in the previous figures. In the

umbilical cord, the serum BA concentrations show intermediate values. Serum CLCA and SLCG levels are similar in the mother, in the umbilical cord, and in the baby.

\section{DISCUSSION}

The most important finding in the present study is that of the high serum CCA and CCDCA levels in the first year of life, compared to adults $(3,7)$ and the children after the first year.

Balistrieri et al. (1), in interpreting their data on the high levels of serum CCA in children, suggested that these results might be due to the frequent food intake which induces continuous EHC stimulation. Our data are not in agreement with this hypothesis. In fact, not only do never-fed newborn babies have serum CCA and CCDCA levels as high as those of fed infants in fasting conditions, but fasting fed premature infants show lower serum $B A$ levels than do never-fed babies.

It seems, therefore, that the high levels of serum CCA and CCDCA pertain specifically to the first wks and months of life regardless of feeding.

Moreover, the high serum CCA and CCDCA levels in premature infants and the relationship between mother and baby serum BA concentrations suggest that the infant's serum BA pattern is due mainly to the persistence of fetal metabolic conditions. In recent studies in monkeys (9), high serum BA levels were found in the fetus, thus demonstrating a bidirectional placental transport.

In all the studied babies, serum BA increase after meals, but with a different behavior with regard both to time and to the rate of increment.

This postprandial increase is probably due to gallbladder emptying, but intestinal absorption may influence the different profile present in both each subject and each BA. Inasmuch as the number of the subjects is very small, it is not possible to make a definitive statement on the different behavior of the two BA, even though experimental studies ( 8 ) have reported both an active and a passive absorption for CCA, whereas CCDCA is mainly absorbed passively.

All these data confirm an unsteady state of the BA pool. Recent studies, in fact, demonstrated that in infants the cholic acid and CCDCA pools are both reduced, probably due to an excessive loss 
of BA from the EHC or to a disorder in BA synthesis. The low BA pool would therefore account for the low intraluminal BA concentrations (8).

It may therefore be concluded that, even if the pool recirculates faster due both to the predominant jejunal passive absorption (short circuit of EHC) (8) and to the frequent meals, the determinants of the high fasting serum BA levels in infants may be identified with a reduced BA clearing capacity by the liver.

BA metabolism in infants is characterized by low intraluminal BA concentrations (11), low BA pool size (19), high BA serum levels (1), and a low BA synthesis rate not unlike that of the adult affected by liver disease $(2,18)$ in which BA uptake, transport, and secretion are impaired and part of the BA pool is redistributed into the liver, serum, and tissue compartments.

The liver has not yet acquired this capacity to clear BA, but gradually improves during the first year.

It should be pointed out that normal serum CLCA and SLCG values were found in all the groups considered. Samuel et al. (15) recently reported that the in vitro 7-alpha dehydroxylase activity of fecal flora on BA increases with the age in infants and children.
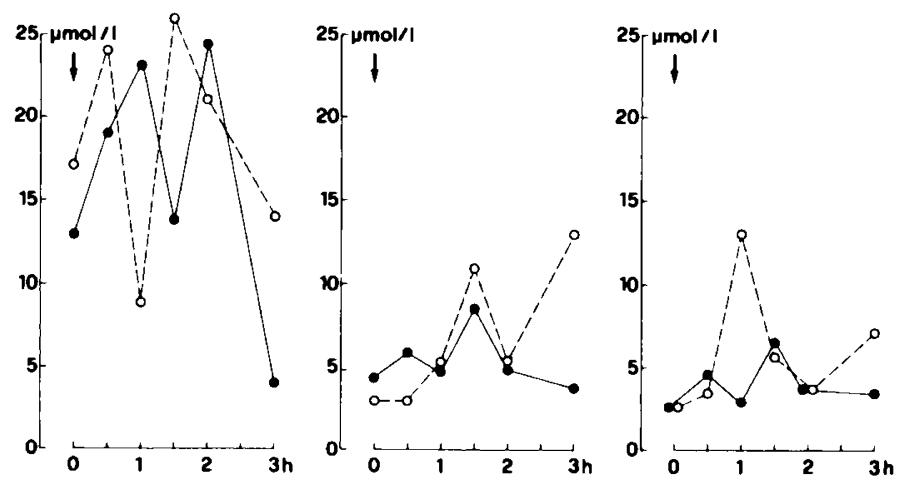

Fig. 3. Serum BA levels in relation to meal $(\downarrow)$ in three normally fed infants during their first month of life. O, CCA:, CCDCA.
Therefore, the microflora pattern (15), the low chenodeoxycholic acid pool size (19), and a poor preservation of lithocholic acid in the EHC (4) could sustain the low intestinal input and subsequently the very low serum CLCA and SLCG values. Our findings are not in contrast to this view and may be explained on the basis of the inefficient BA clearing capacity by the liver in infants. The BA sulfation capacity seems to be active at birth (20), working as protective excretory pathway.

In summary, fasting serum CCA and CCDCA levels are higher in infants that in adults, but fall progressively within the first year of life to levels not unlike those found in healthy adults.

Serum CLCA and SLCG do not differ between children and adults.

BA pattern are not sex-related. In uncomplicated pregnancy, no increase in serum BA levels is observed in the mother's sera and values in the umbilical cord are intermediate between those of mothers and children.

In premature infants, the first food in life brings about a decrease in serum CCA and CCDCA levels. No difference is observed in normal infants. These data suggest a new distribution of the BA pool from the peripheral compartment to the biliary tract and intestine. In infants, as in the adult, elevations in serum levels of primary BA are meal-related, thus suggesting that gallbladder motility is almost normal (12).

These data appear to support the concept of immaturity of the hepatic uptake system of $\mathrm{BA}$ in infants and suggest that determination of serum CCA and CCDCA levels may be usefully used in the diagnosis of neonatal liver disease.

\section{REFERENCES AND NOTES}

I. Balistrieri, W. F., Korman, M. G.. Turcotte, J., and Hofmann, A. F.: Radioimmunoassay of serum conjugates of cholic acid in infants and children. Pediatr. Res. (Abstract), 9: 301 (1975).

2. Barbara, L.: Bile acids as markers of liver disease. Ital. J. Gastroenterol. 10 (Suppl 1): 8 (1978).

3. Barbara, L., Roda, A., Roda, E., Aldini, R., Mazzella. G., Festi, D., and Sama. C.: Diurnal variations of serum primary bile acids in healthy subjects and hepatobiliary disease patients. Rend. Gastroenterol., 8: 194 (1976)

4. Cowen, A. E., Korman, M. G., Hofmann. A. F.. Cass, O. W., and Coffin, S. B.
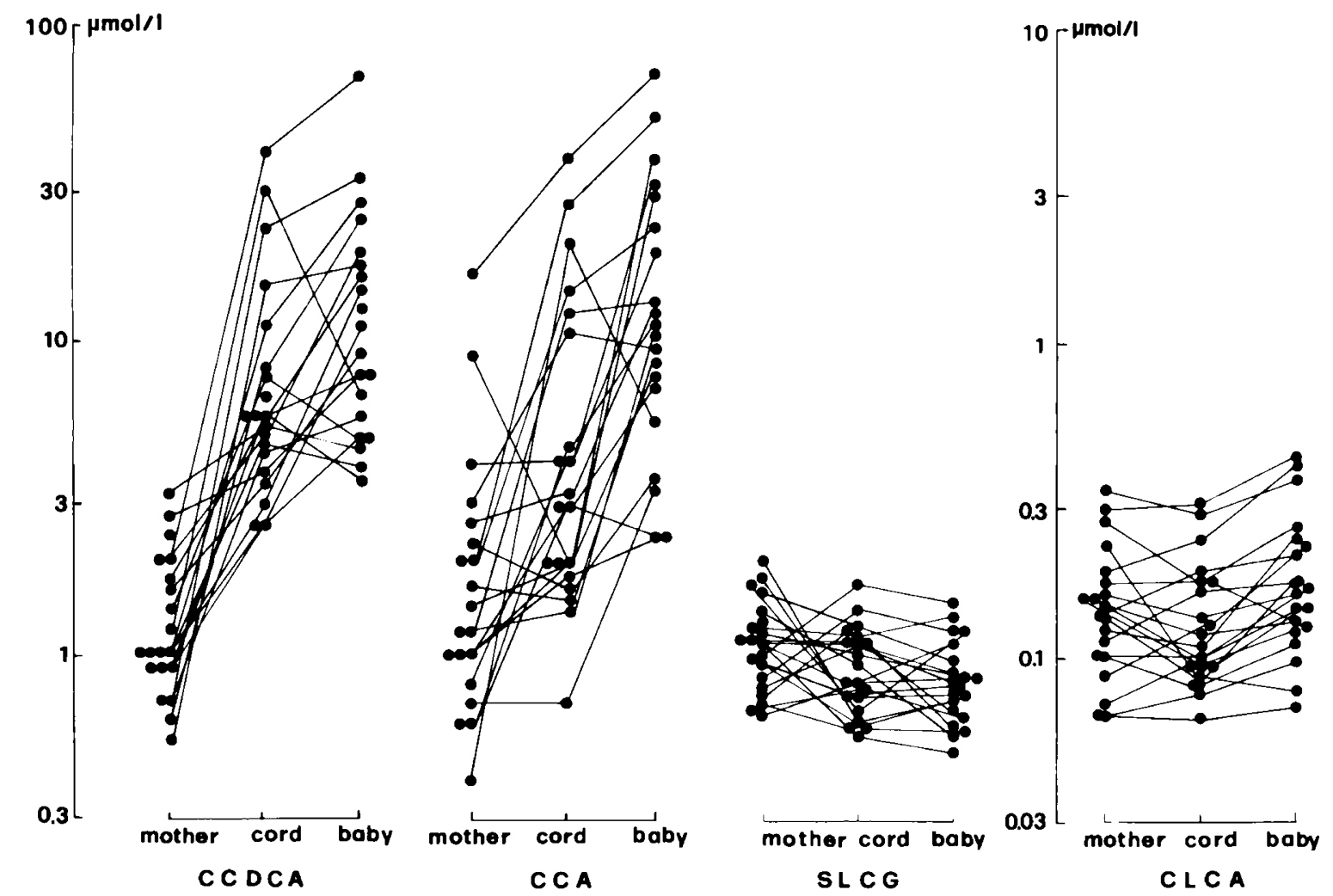

Fig. 4. BA concentrations in blood of mother, umbilical cord, and baby. 
Metabolism of lithocholate in healthy man. II. Enterohepatic circulation. Gastroenterology, 69: 67 (1975).

5. Javitt. N. B., Morrissey, K. P., Siegel, E., Goldberg. H., Gartner, L. M., Hollander, $M$., and Kok, E.: Cholestatic syndromes in infancy: diagnostic value of serum bile acid pattern and response to cholestyramine. Pediatr. Res.. 7: 119 (1973).

6. Katz, L., and Hamilton, J. R.: Fat absorption in infants of birthweight less than 1300 grams. J. Pediatr., 85: 608 (1974).

7. La Russo, N. F., Korman, M. G., Hoffman, N. E., and Hofmann, A. F. Dynamics of the enterohepatic circulation of bile acids. N. Engl. J. Med., 291: 689 (1974).

8. Lester. R., Smallwood, R. A., Little, J. M., Brown, A. S., Piasecki, G. J., and Jackson, B. T.: Fetal bile salt metabolism. The intestinal absorption of bile salt. J. Clin. Invest., 59: 1009 (1977).

9. Litle M Smallwood, R. A. Lester, R.. Piasecki, G. J., and Jackson, B. T.: Bilesalt metabolism in the primate fetus. Gastroenterology. 69: 1315 (1975).

10. Norman, A.. Strandvik, B., and Ojamae, O.: Bile acids and pancreatic enzymes during absorption in the newborn. Acta Pediatr. Scand., 61: 571 (1972).

11. Poley, J. R., Dower. J. C., Owen, C. A., Jr., and Stickler, G. B.: Bile acids in infants and children. J. Lab. Clin. Med., 63: 838 (1964).

12. Roda, E., Aldini, R.. Mazzella, G., Roda. A.. Sama. C.. Festi. D.. and Barbara, L.: Enterohepatic circulation of bile acids after cholecystectomy. Gut, 19:640 (1978).

13. Roda, A., Roda, E., Aldini, R., Festi, D., Mazzella, G., Sama. C., and Barbara. L.: Development, validation and application of a single-tube radioimmunoassay for cholic and chenodeoxycholic conjugated bile acids in human serum.
Clin. Chem., 23: 2107 (1977)

14. Roda, A. Roda. E., Festi, D., Aldini, R., Mazzella. G.. Sama. C., and Barbara. L.: A radioimmunoassay for lithocholic acid conjugates in human serum and liver tissue. Steroids, 32: 13 (1978).

15. Samuel. P.. Schussheim. A., Lieberman, S., and Don, E. C.: Relation of serum cholesterol to in vitro $7 \alpha$-dehydroxylation of primary bile acids by fecal bacteria in infants and children. Pediatrics, 54: 222 (1974).

16. Sandberg. D. H.: Bile acid concentrations in serum during infancy and childhood. Pediatr. Res., 4: 262 (1970)

17. Simmonds, W. J., Korman, M. G., Go, V. L. W., and Hofmann. A. F.: Radioimmunoassay of conjugated cholyl bile acids in serum. Gastroenterology, 65: 705 (1973).

18. Stiehl, A., Ast, E., Czygan, P., Fröhling. W., Raedsch, R., and Kommerell. B.: Pool size, synthesis, and turnover of sulfated and nonsulfated cholic acid and chenodeoxycholic acid in patients with cirrhosis of the liver. Gastroenterology, 74: $572(1978)$

19. Watkins, J. B., Ingall, D., Szczepanik, P. A., Klein, P. D., and Lester, R.: Bile-salt metabolism in the newborn. Measurement of pool size and synthesis by stable isotope technique. N. Engl. J. Med.. 288: 431 (1973).

20. Watkins, J. B., Szczepanik, P. A., and Klein, P. D.: Sulfated bile acid conjugates in human fetal tissue. Gastroenterology (Abstract), 70: 996 (1976).

21. Requests for reprints should be addressed to: Luigi Barbara. Department of Gastroenterology, S. Orsola Hospital, Via Massarenti, 9, Bologna, Italy.

22. Received for publication September 6, 1979.

23. Accepted for publication January 23, 1980. 